\title{
A comparison of the clinical effect of two fixation methods on Hoffa fractures
}

\author{
Yi Xu ${ }^{1}$, Heng Li ${ }^{1}$, Hong-hang Yang ${ }^{1}$ and Zhi-jun Pan ${ }^{2 *}$
}

\begin{abstract}
Introduction: Hoffa fractures are rare and difficult to treat for orthopaedic surgeons. The mechanism of injury of Hoffa fracture is still unknown and the operation approch and fixation method are still controversial. The aim of this study is to compare the clinical effect between two fixation methods on Hoffa fractures.

Case description: From April 2004 to July 2013, we treated eleven patients (new method group) with Hoffa fracture using the new fixation method (fixed with intercondylar screw and crossed screws) and sixteen patients (traditional method group) using the traditional fixation method (fixed with anteroposteriorly placed screws). All documents from their admission until the last followup in December 2015 were reviewed, data regarding complications collected and results were evaluated using the Knee Society Score.

Discussion and Evaluation: After an average follow-up period of 27.1 months (range 24-32 months), all fractures had healed. The average healing time of the new method group was 11.36 weeks (range 9-14 weeks) and the average healing time of the traditional method group was 11.88 weeks (range 9-14 weeks). According to the Knee Society Score, the average score of the new method group was 176.36 points (range 125-199 points), and the average score of the traditional method group was 171.19 points (range 148-197 points). Statistical analysis ( $t$ test, $t=0.76, P>0.05$ ) showed that the difference of both the healing time ( $t$ test $t=0.94, P>0.05$ ) and the score between these two groups was not significant.
\end{abstract}

Conclusions: These results indicate that the new fixation method for Hoffa fracture is as effective as the traditional method and may provide a new way to treat Hoffa fractures.

Keywords: Hoffa fracture, Femoral intercondylar notch, Open reduction and internal fixation

\section{Background}

Hoffa fractures are rare injuries that are first described by Hoffa (1904). Nonoperative treatment of Hoffa fractures usually results in poor outcomes (Ostermann et al. 1994; Lewis et al. 1989; Borse et al. 2010; Jarit et al. 2006). So anatomic reduction and rigid internal fixation of Hoffa fractures are very important to allow early knee motion and help knee functional recovery. Since April 2004, we treated Hoffa fractures using a new fixation method (fixed with intercondylar screw and crossed screws) and achieved good results (Xu et al. 2013). We report our

\footnotetext{
*Correspondence: 13857290270@163.com

2 Department of Orthopaedic Surgery, The Second Affiliated Hospital, School of Medicine, Zhejiang University, Hangzhou 310009, Zhejiang, China

Full list of author information is available at the end of the article
}

results of treating Hoffa fractures by two fixation methods and review the literatures concerning the treatment of Hoffa fractures.

\section{Patients and methods}

In a retrospective study, twenty-seven patients who underwent open reduction and internal fixation for unicondylar Hoffa fractures between April 2004 to July 2013 were enrolled. Eleven patients (new method group) were treated by the new fixation method (fixed by intercondylar screw and crossed screws). There were eight males and three females, aged from 23 to 48 years (average 38.45 years). Eight fractures were lateral, and three were medial. The mechanism of injury was a motor vehicle accident in all patients. According to Letenneur classification (Letenneur et al. 1978), seven fractures were type 
I and four were type III. Preoperative X-rays of one of ten cases were shown in Fig. 1. Sixteen patients (traditional method group) were treated by the traditional method (fixed by anteroposteriorly placed screws). There were eleven males and five females, aged from 20 to 51 years (average 38.19 years). Twelve fractures were lateral, and four were medial. The mechanism of injury was a motor vehicle accident in fourteen patients and a fall in two patients. According to Letenneur classification, ten fractures were type I and six were type III. Preoperative X-rays of one of sixteen cases were shown in Fig. 2. According to $F$ test, the difference of both age $(F=1.21$, $P>0.05)$ and type $(F=1.19, P>0.05)$ between these two groups was not significant.

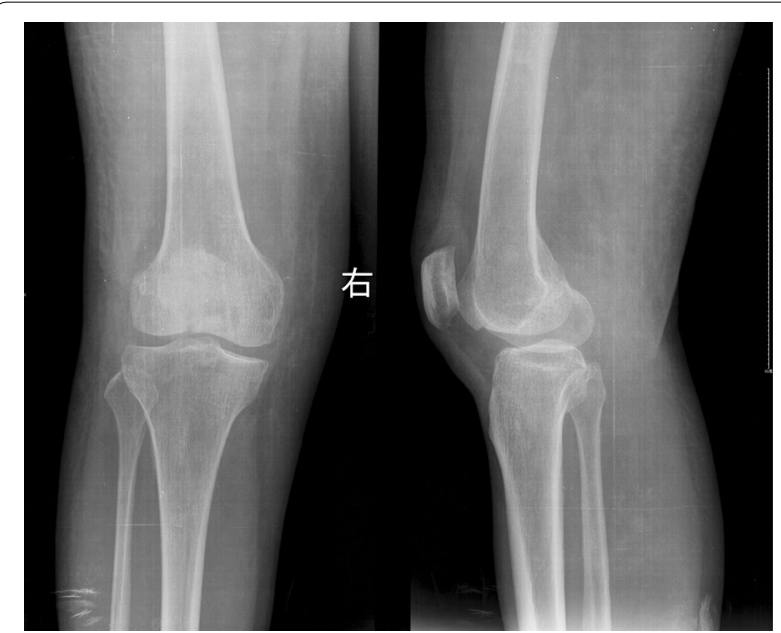

Fig. 1 Anteroposterior and lateral radiographs show Hoffa fracture (type III) of the lateral femoral condyle
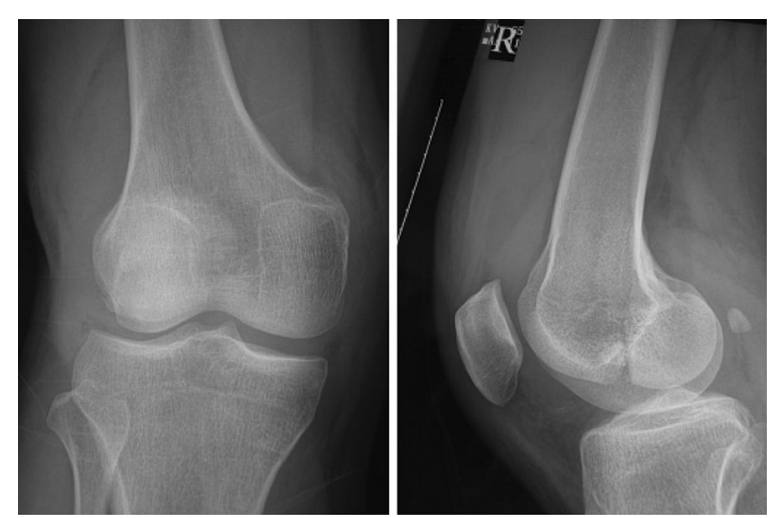

Fig. 2 Anteroposterior and lateral radiographs show Hoffa fracture (type I) of the lateral femoral condyle

\section{Operative procedure}

Under general anaesthesia, an anterolateral (or anteromedial) incision is made, with lateral (or medial) parapatellar release and medial (or lateral) dislocation of the patella, the fractured condyle is exposed. With full flexion of the knee, the fracture can be exposed clearly. Using a bone repositioning clamp to hold the fracture fragment, the fracture can be reduced by traction of the calf and slow stretching of the knee. Then the knee is flexed again and the fracture is preliminarily fixed with two Kirschner wires. The fracture is fixed by three cancellous screws. One screw (3.5- or $4.5-\mathrm{mm}$ ) is inserted from the femoral intercondylar notch (Fig. 3) and is directed anterolaterally (or anteromedially) to thread through the fractured condylar fragment. The other two screws $(6.5-\mathrm{mm})$ are inserted from the nonarticular lateral (or medial) surface of the fractured condylar fragment, and are directed medially (or laterally) to thread through the fractured condylar fragment (Fig. 4). One of these two screws is placed in a certain angle to reach the opposite femoral shaft. Two sides of screws are crossed.

The traditional method use the same approach, but the fracture is fixed with two parallel screws. The screws are inserted from the non-articular area just proximal to the patellafemoral joint with an anteroposterior direction to engage the fractured condylar fragment (Fig. 5).

Postoperatively, all patients began unrestricted range of motion. Initial weight-bearing status was limited, but all patients were allowed full weight bearing within 3 months.

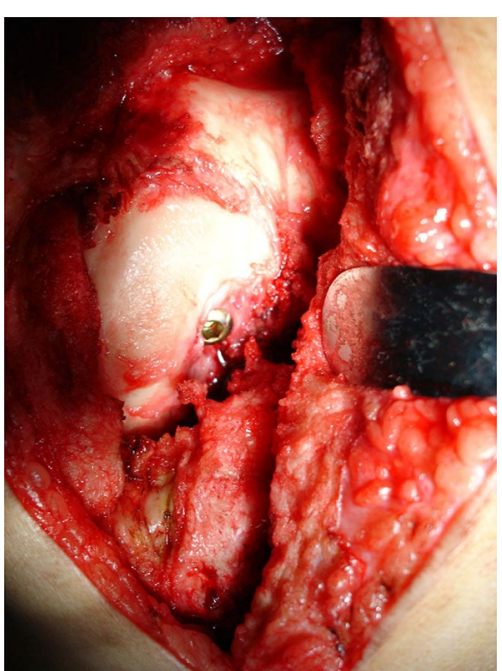

Fig. 3 The screw is inserted from the femoral intercondylar notch 


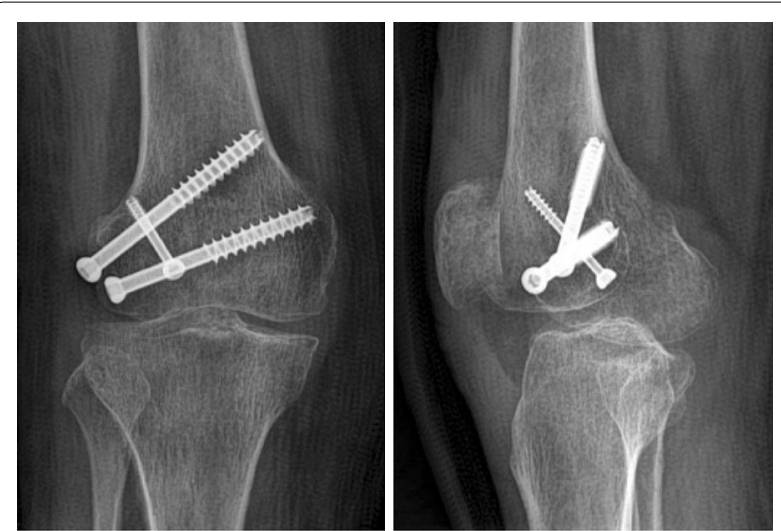

Fig. 4 Anteroposterior and lateral radiograph shows the fracture is fixed with three screws, one screw is inserted from the femoral intercondylar notch

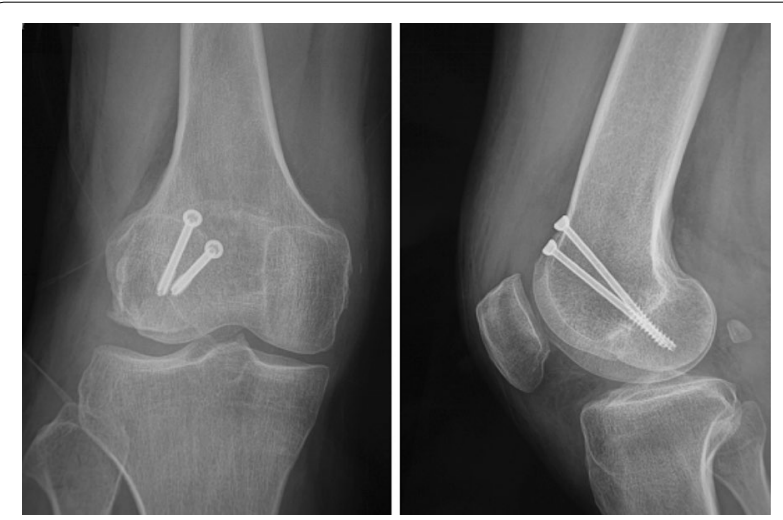

Fig. 5 Anteroposterior and lateral radiograph shows the fracture is fixed with two anteroposterior parallel screws

\section{Statistical analysis}

Statistical analyses were performed using SPSS version 13.0 (SPSS Inc, Chicago, IL) for Windows. Data are shown as mean \pm standard error of the mean, except where indicated otherwise. The Student's $t$ test was used to compare continuous variables. The Chi square test was used to evaluate the differences in clinical outcomes between potential associated factors. $P$ values below 0.05 were accepted for statistical significance.

\section{Results}

After an average follow-up period of 27.07 months (range 24-32 months), all of the fractures healed both clinically and radiologically, without deep infection, nonunion, malunion, osteonecrosis and hardware removals. The healing time of the new method group was $11.36 \pm 1.36$ weeks (range 9-14 weeks) and the average healing time of the traditional method group was $11.88 \pm 1.41$ weeks (range 9-14 weeks). According to the
Knee Society Score, the score of the new method group was $176.36 \pm 20.65$ points (Table 1 ), and the score of the traditional method group was $171.19 \pm 15.04$ points (Table 2). Statistical analysis showed that the difference of both the healing time ( $t$ test, $t=0.94, P>0.05$ ) and the score ( $t$ test, $t=0.76, P>0.05)$ between these two groups was not significant.

\section{Discussion}

Hoffa fractures are unstable intraarticular fractures, and lateral Hoffa fractures are more common than medial ones (Ostermann et al. 1994; Xu et al. 2013; Letenneur et al. 1978; Nork et al. 2005; Dhillon et al. 2012; Biau and Schranz 2005). Bicondylar Hoffa fractures are rare (Papadopoulos et al. 2004; Calmet et al. 2004). In our study, there are twenty lateral Hoffa fractures and seven medial Hoffa fractures, which is similar to the literatures. The mechanism of injury of Hoffa fracture is still unknown. Some authors consider direct impact with the knee in a flexed position as the mechanism of injury, while others think that the fracture is caused by simultaneous vertical shear and twisting forces (Lewis et al. 1989; Papadopoulos et al. 2004). In initial anteroposterior and lateral radiographs, Hoffa fractures, especially when nondisplaced, are sometimes difficult to be observed. So a CT scan or MRI scan is necessary to define the fractures (Nork et al. 2005)

Hoffa fracture is classified as a type 33-B3 fracture by the Orthopaedic Trauma Association. But this classification provides little information of prognosis and treatment. Letenneur et al. (1978) reported that they divided Hoffa fractures into three types based on the distance of the fracture line from the posterior cortex of the femoral shaft. In a cadaveric study, Lewis et al. (1989) finded that in Type I and Type III Hoffa fractures there are some soft tissue elements attached to the fractured condylar fragment to provide blood supply to this fragment. But in Type II Hoffa fractures there was no soft tissue elements attached to the fractured condylar fragment.

Hoffa fractures are intraarticular fractures. Most of them need surgical open reduction and internal fixation to achieve good outcome (Lewis et al. 1989; Letenneur et al. 1978; McDonough and Bernstein 2000; Manfredini et al. 2001). But the operation approach and fixation method are still been improving. It is generally accepted that screw fixation is a good fixation method for treating Hoffa fractures. In Type I and Type III Hoffa fractures, an anterolateral (or anteromedial) incision is usually used, and two anteroposteriorly placed lag screws are inserted from the non-articular area just proximal to the patella-femoral joint to engage the fractured condylar fragment. One screw is inserted into the femoral shaft to provide rotational stability (Ostermann et al. 1994). 
Table 1 Information and results of the patients in the new method group

\begin{tabular}{|c|c|c|c|c|c|c|c|c|}
\hline \multirow[t]{2}{*}{ Case } & \multirow[t]{2}{*}{ Gender } & \multirow{2}{*}{$\begin{array}{l}\text { Age } \\
\text { (years) }\end{array}$} & \multirow{2}{*}{$\begin{array}{l}\text { Lateral or } \\
\text { medial }\end{array}$} & \multirow[t]{2}{*}{ Type } & \multicolumn{4}{|l|}{ Results } \\
\hline & & & & & $\begin{array}{l}\text { Time of fractures } \\
\text { healing (weeks) }\end{array}$ & $\begin{array}{l}\text { Objective score } \\
\text { (points) }\end{array}$ & $\begin{array}{l}\text { Functional score } \\
\text { (points) }\end{array}$ & $\begin{array}{l}\text { Total score } \\
\text { (points) }\end{array}$ \\
\hline 1 & $\mathrm{~F}$ & 36 & Lateral & I & 9 & 76 & 80 & 156 \\
\hline 2 & $M$ & 23 & Lateral & 1 & 12 & 94 & 100 & 194 \\
\hline 3 & $M$ & 45 & Lateral & 1 & 11 & 89 & 80 & 169 \\
\hline 4 & $M$ & 48 & Medial & I & 11 & 88 & 100 & 188 \\
\hline 5 & $M$ & 32 & Medial & III & 10 & 88 & 90 & 178 \\
\hline 6 & $\mathrm{~F}$ & 44 & Medial & I & 13 & 89 & 97 & 186 \\
\hline 7 & $M$ & 46 & Lateral & III & 12 & 65 & 60 & 125 \\
\hline 8 & $M$ & 40 & Lateral & III & 11 & 90 & 90 & 180 \\
\hline 9 & $\mathrm{~F}$ & 42 & Lateral & 1 & 14 & 95 & 90 & 185 \\
\hline 10 & $M$ & 27 & Lateral & 1 & 11 & 99 & 100 & 199 \\
\hline 11 & $M$ & 40 & Lateral & III & 11 & 90 & 90 & 180 \\
\hline
\end{tabular}

Table 2 Information and results of the patients in the traditional method group

\begin{tabular}{|c|c|c|c|c|c|c|c|c|}
\hline \multirow[t]{2}{*}{ Case } & \multirow[t]{2}{*}{ Gender } & \multirow{2}{*}{$\begin{array}{l}\text { Age } \\
\text { (years) }\end{array}$} & \multirow{2}{*}{$\begin{array}{l}\text { Lateral } \\
\text { or medial }\end{array}$} & \multirow[t]{2}{*}{ Type } & \multicolumn{4}{|l|}{ Results } \\
\hline & & & & & $\begin{array}{l}\text { Time of fractures } \\
\text { healing (weeks) }\end{array}$ & $\begin{array}{l}\text { Objective score } \\
\text { (points) }\end{array}$ & $\begin{array}{l}\text { Functional score } \\
\text { (points) }\end{array}$ & $\begin{array}{l}\text { Total score } \\
\text { (points) }\end{array}$ \\
\hline 1 & $F$ & 36 & Lateral & 1 & 9 & 83 & 95 & 178 \\
\hline 2 & $M$ & 49 & Medial & 1 & 11 & 80 & 75 & 155 \\
\hline 3 & $M$ & 26 & Lateral & 1 & 11 & 80 & 82 & 162 \\
\hline 4 & $M$ & 42 & Lateral & 1 & 14 & 95 & 99 & 194 \\
\hline 5 & $M$ & 32 & Medial & III & 10 & 91 & 94 & 185 \\
\hline 6 & $M$ & 20 & Lateral & 1 & 12 & 75 & 87 & 162 \\
\hline 7 & $M$ & 46 & Lateral & III & 11 & 71 & 82 & 153 \\
\hline 8 & $\mathrm{~F}$ & 44 & Medial & III & 14 & 78 & 80 & 158 \\
\hline 9 & $M$ & 30 & Lateral & 1 & 13 & 85 & 95 & 180 \\
\hline 10 & $F$ & 33 & Lateral & 1 & 12 & 78 & 70 & 148 \\
\hline 11 & $M$ & 51 & Lateral & III & 13 & 85 & 84 & 169 \\
\hline 12 & $M$ & 46 & Medial & 1 & 11 & 98 & 99 & 197 \\
\hline 13 & $\mathrm{~F}$ & 39 & Lateral & I & 13 & 79 & 96 & 175 \\
\hline 14 & $M$ & 46 & Lateral & III & 13 & 85 & 91 & 176 \\
\hline 15 & $\mathrm{~F}$ & 35 & Lateral & III & 12 & 90 & 97 & 187 \\
\hline 16 & $M$ & 36 & Lateral & 1 & 11 & 80 & 80 & 160 \\
\hline
\end{tabular}

In Type II Hoffa fractures, because the fracture line is near the articular cartilage of the posterior condyle, a posterior approach and two posteroanteriorly placed lag screws may be a good choice (Medvecky and Noyes 2005; Tan et al. 2013). However, the screws are inserted through the articular surface, so the screw heads should be countersunk.

In our study, the new fixation method use only three screws. One screw is inserted into the femoral intercondylar notch to avoid affecting the knee function by the articular surface defect and decreases the risk of osteoarthritis. The other two screws are inserted from the non-articular lateral (or medial) surface of the fractured condylar fragment, two sets of screws are crossed, so both sides of the fracture lines are completely compressed. Three screw heads are shaped into a triangle, which can protect against shear and twisting forces and obtain better stabilization. We also find that this new method is more suitable for type III Hoffa fractures. Because in type III Hoffa fractures, the fracture line is oblique and the fracture fragment in the intercondylar notch is big enough to insert a screw. But in type I Hoffa 
fractures, the fracture line is vertical and the screw entry point must be closed to the weight-bearing area of the articular cartilage.

Jarit et al. (2006) reported that Lag screws placed in a posteroanterior direction were more stable than anteroposteriorly placed lag screws. In our new method, the screws are not placed in a posteroanterior direction, which is an imperfection. But the crossed screws are more rigid than the parallel screws, especially in resisting torsional stresses (Friedman et al. 1994).

Becker et al. (2000) had a cadaveric study to compare the stiffness and load to failure among $3.5-\mathrm{mm}$ cortical lag screws, $4.5-\mathrm{mm}$ cortical lag screws, and $6.5-\mathrm{mm}$ cancellous screws to fix experimentally created Hoffa fractures. There was no difference in stiffness between these three groups, but compared with $3.5-\mathrm{mm}$ screws, the load to failure was significantly higher for $6.5-\mathrm{mm}$ screws. We inserted a $3.5-\mathrm{mm}$ or $4.5-\mathrm{mm}$ screw from the femoral intercondylar notch to decrease articular cartilage defects. But the other two screws were $6.5-\mathrm{mm}$ screws to bear more loads.

However, in our study there is no direct evidence shows that the stability of the new method is better than the traditional method, which needs a further mechanical study. And the difference of the risk of osteoarthritis between these two methods needs a long-term follow-up.

In a summary, the results of our study show that the new fixation method for Hoffa fracture is as effective as the traditional method and this new fixation method may be more suitable for type III Hoffa fractures.

\section{Authors' contributions}

$Y X, H L, H Y$ and ZP carried out the study. YX drafted the manuscript. All authors read and approved the final manuscript.

\section{Author details \\ ${ }^{1}$ Department of Orthopaedics, The First People's Hospital of Huzhou (The First Affiliated Hospital of Huzhou Teachers College), Zhejiang University, Huzhou 313000, Zhejiang, China. ${ }^{2}$ Department of Orthopaedic Surgery, The Second Affiliated Hospital, School of Medicine, Zhejiang University, Hang- zhou 310009, Zhejiang, China.}

\section{Acknowledgements}

This study is supported by Huzhou Science and Technology Bureau (No. 2014GY10).

\section{Competing interests}

All authors declare that they have no competing interests.

\section{Ethical statement}

All authors (Yi Xu, Heng Li, Hong-hang Yang and Zhi-jun Pan) state that all human studies have been approved by the appropriate ethics committee and have therefore been performed in accordance with the ethical standards laid down in the 1964 Declaration of Helsinki and its later amendments and specific national laws have been observed.

Received: 18 February 2016 Accepted: 18 July 2016

Published online: 25 July 2016

\section{References}

Becker P, Staford PR, Goulet R et al (2000) Comparative analysis for the fixation of coronal distal intraarticular femur fractures. The 67th annual meeting of the American Academy of Orthopaedic Surgeons, pp 15-19

Biau DJM, Schranz PJ (2005) Transverse Hoffa's or deep osteochondral fracture? An unusual fracture of the lateral femoral condyle in a child. Injury 36(7):862-865

Borse V, Hahnel J, Cohen A (2010) Hoffa fracture: fixation using headless compression screws. Eur J Trauma Emerg Surg 36(5):477-479

Calmet J, Mellado JM, Garcia Forcada IL et al (2004) Open bicondylar Hoffa fracture associated with extensor mechanism injury. J Orthop Trauma 18(5):323-325

Dhillon MS, Mootha AK, Bali K et al (2012) Coronal fractures of the medial femoral condyle: a series of 6 cases and review of literature. Musculoskelet Surg 96(1):49-54

Friedman RL, Glisson RR, Nunley JA 2nd (1994) A biomechanical comparative analysis of two techniques for tibiotalar arthrodesis. Foot Ankle Int 15(6):301-305

Hoffa A (1904) Lehrbuch der Frakturen und Luxationen, 4th edn. Ferdinan Enke Verlag, Stuttgart, p 453

Jarit GJ, Kummer FJ, Gibber MJ et al (2006) A mechanical evaluation of two fixation methods using cancellous screws for coronal fractures of the lateral condyle of the distal femur (OTA type 33B). J Orthop Trauma 20(4):273-276

Letenneur J, Labour PE, Rogez JM et al (1978) Hoffa's fracture: report of 20 cases. Ann Chir 32(3):213-219

Lewis SL, Pozo JL, Muirhead-Allwood WF (1989) Coronal fracture of the lateral femoral condyle. J Bone Joint Surg [Br] 71(1):118-120

Manfredini M, Gildone A, Ferrante R et al (2001) Unicondylar femoral fractures: therapeutic strategy and long-term results. A review of 23 patients. Acta Orthop Belg 67(2):132-138

McDonough PW, Bernstein RM (2000) Nonunion of a Hoffa fracture in a child. J Orthop Trauma 14(7):519-521

Medvecky MJ, Noyes FR (2005) Surgical approaches to the posteromedial and posterolateral aspects of the knee. J Am Acad Orthop Surg 13(2):121-128

Nork SE, Segina DN, Aflatoon K et al (2005) The association between supracondylar intercondylar distal femoral fractures and coronal plan fractures. J Bone Joint Sur (Am) 87(3):564-569

Ostermann PA, Neumann K, Ekkernkamp A et al (1994) Long term results of uniconylar fractures of the femur. J Orthop Trauma 8(2):142-146

Papadopoulos AX, Panagopoulos A, Karageorgos A et al (2004) Operative treatment of unilateral bicondylar Hoffa fractures. J Orthop Trauma 18(2):119-122

Tan Y, Li H, Zheng Q et al (2013) A modified posterolateral approach for Hoffa fracture. Eur J Orthop Surg Traumatol 24(7):1321-1323

Xu Y, Li H, Yang HH (2013) A new fixation method for Hoffa fracture. Eur J Trauma Emerg Surg 39(1):87-91

\section{Submit your manuscript to a SpringerOpen ${ }^{\circ}$ journal and benefit from:}

- Convenient online submission

- Rigorous peer review

- Immediate publication on acceptance

- Open access: articles freely available online

- High visibility within the field

- Retaining the copyright to your article

Submit your next manuscript at springeropen.com 